\title{
O PLANEJAMENTO COLABORATIVO NO ENSINO DA ESTATÍSTICA: INSTRUMENTO PARA FORMAR DISCENTES E DOCENTES
}

Maria Tereza Serrano Barbosa, Luciane Velasque, Alexandre Souza e Silva, Maria Beatriz Cunha, Bruno Simões, Steven Ross, Felipe Ribeiro.

Universidade Federal do Estado do Rio de Janeiro (UNIRIO), Brasil

felipe.ribeiro@uniriotec.br

O trabalho em colaboração é hoje valorizado nas empresas e nos setores de governo, mas é raro que o planejamento de um componente seja realizado por equipes de docentes. O isolamento da Universidade em relação à sociedade e a interpretação de que a autonomia universitária refere-se à individualidade do docente, são fatores que não incentivam à constituição de equipes para planejar e executar. A experiência relatada demonstra como o estabelecimento desta parceria pode ser mais eficiente e prazeroso para os docentes e discentes.

\section{INTRODUÇÃO}

Deveria fazer parte da missão das Universidades formar pessoas que cultivem e contribuam com uma cultura de ética, paz, solidariedade e consciência planetária. Esta formação, aliada ao estímulo ao trabalho em parceria para a resolução de problemas, ao desenvolvimento da criatividade e da capacidade de crítica comporiam as habilidades que deveriam ser avaliadas para a definição da excelência acadêmica de uma instituição. No entanto, como formar profissionais com estas habilidades se o trabalho docente nas Universidades é, de maneira geral, completamente individual e sem conexão com os objetivos mais amplos da instituição, do curso ou mesmo da disciplina ministrada? Apesar do trabalho em colaboração (Donato, 2007; Julianelli, 2006) ser hoje bastante valorizado nas empresas mais modernas e nos setores de governo, verificamos que na Universidade ainda é raro um planejamento de uma disciplina ser realizado por uma equipe de docentes. Assim, por um lado, vemos o isolamento da Universidade em relação às necessidade da sociedade e, por outro, verificamos que a autonomia universitária é interpretada muitas vezes como um reforço ao trabalho individualizado do docente.

Estas reflexões, aliadas à constatação de que as disciplinas de Estatística oferecidas aos mais diversos cursos da UNIRIO estavam desconectadas das realidades e interesses dos estudantes e não conseguiam despertar motivação nos mesmos, motivou o grupo de professores a iniciar uma mudança na metodologia utilizada. Este trabalho apresentará as etapas percorridas e os resultados obtidos.

\section{PROCEDIMENTOS METODOLÓGICOS}

Primeira Etapa: No momento inicial desta experiência, quatro docentes que ministravam o componente curricular de Estatística para oito cursos a cada semestre reuniram-se para troca de experiências e percepções a respeito das dificuldades encontradas para motivar os estudantes de cursos da área da saúde, exatas e humanas sobre a importância desta aprendizagem. Neste momento, nos apropriamos de conceitos e experiências voltadas à Aprendizagem Baseada em Problemas (Bouhuijs, Schmidt, \& Berkel, 1993) e também Aprendizagem por Projetos (Thomas, 2000).

Segunda Etapa: Definição de Objetivos e Habilidades a serem adquiridos pelos estudantes.

Terceira Etapa: Planejamento de atividades com definição das questões motivadoras, e de um tema comum para ser trabalhado e desenvolvido pelos alunos de todas as turmas e apresentados em formato de artigo, em pôsteres ou mesmo com comunicação oral em um mesmo dia.

Quarta Etapa: Reunião com os coordenadores de curso e diretores de escola para informar a mudança de metodologia e convidá-los a participar de reuniões específicas para a elaboração de questões específicas de cada área.

Quinta Etapa: Apresentação Final e avaliação conjunta.

In: M.A. Sorto (Ed.), Advances in statistics education: developments, experiences and assessments. Proceedings of the Satellite conference of the International Association for Statistical Education (IASE), July 2015, Rio de Janeiro, Brazil. 
Etapa atual: Nestes dois anos, três novos docentes incorporaram-se ao grupo trazendo seus olhares e propostas que são experimentadas em mais de dez turmas por semestre com um evento de finalização acontecendo durante um dia inteiro com participação de mais de 250 alunos.

\section{RESULTADOS}

O Planejamento da disciplina feito em colaboração trouxe vantagens para o desenvolvimento do componente curricular, sendo a maior delas a integração e discussão constante do grupo de docentes a respeito dos resultados obtidos em sala de aula. Além disso, o compartilhamento de atividades, planos de Ensino e avaliação permitiu não só a integração entre discentes de diversos cursos, como também que cada docente pudesse se dedicar a um tema onde possuísse mais afinidade e experiência. E isto deu início à proposta de uma nova metodologia de ensino de Estatística.

As Imagens 1 e 2 mostram o dia da apresentação do trabalho final dos diversos cursos de graduação, onde todos os alunos se apresentaram e também assistiram a apresentação dos colegas. Avaliamos que este é um dos momentos mais ricos advindo do uso desta nova metodologia, pois é um momento de integração e compartilhamento de saberes entre os alunos.

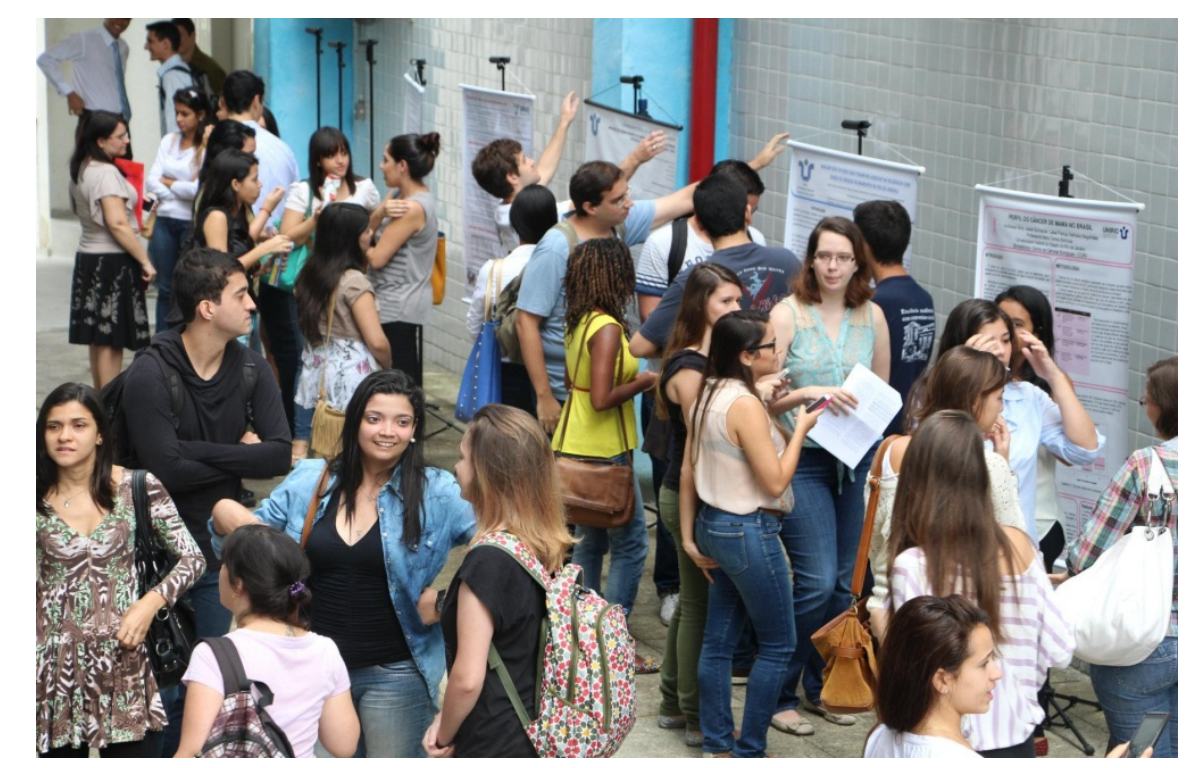

Imagem 1: Apresentação do trabalho final no formato pôster, UNIRIO-2014. 


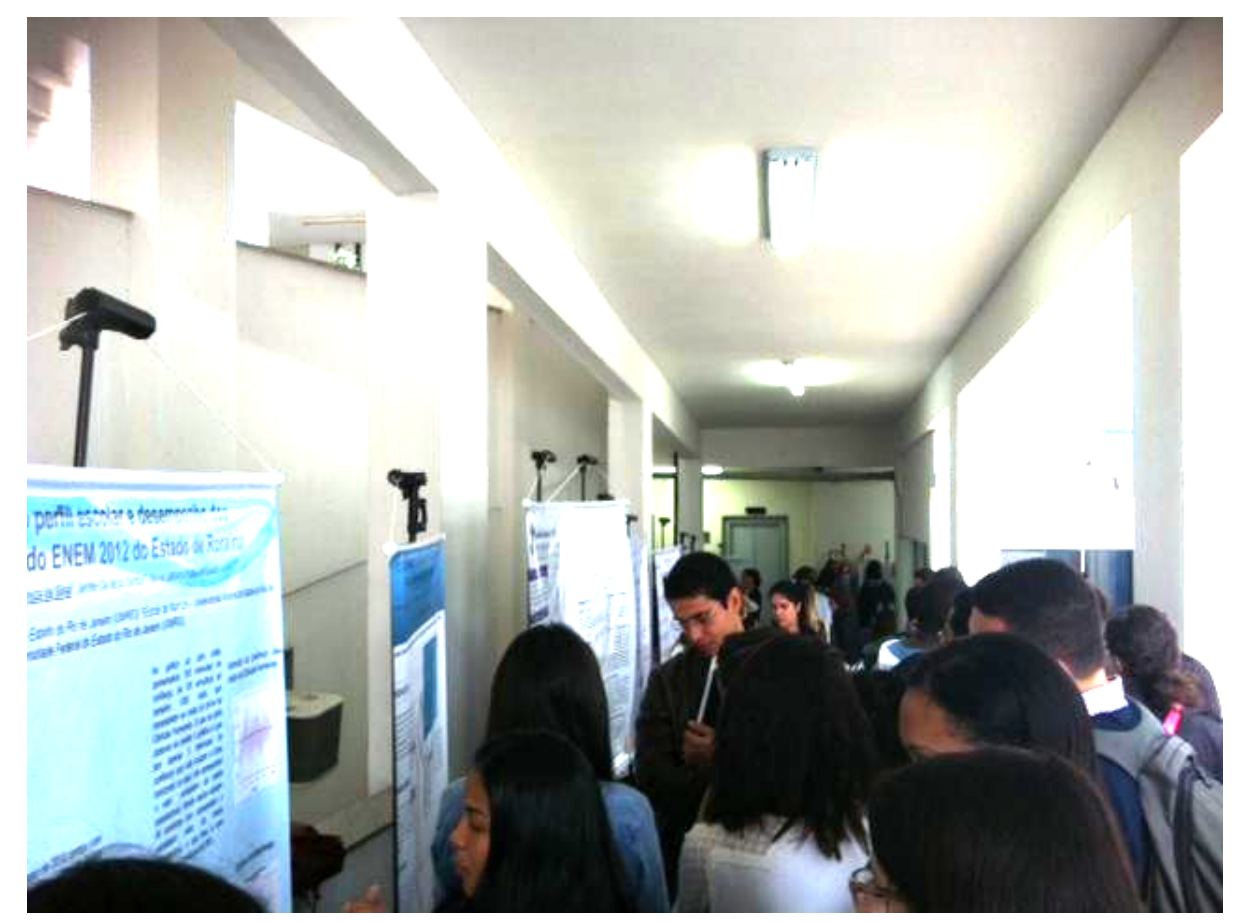

Imagem 2: Apresentação do trabalho final no formato pôster, UNIRIO-2014.

Outro resultado importante é que esta nova metodologia permite que os alunos passem a explorar temas que vão além do inicialmente previsto, como conteúdo programático da disciplina. Esse fato permite que cada aluno possa ampliar bastante seu conhecimento sobre a aplicação da Estatística nos mais diversos cenários e nas diversas áreas do conhecimento. A Imagem 3 mostra trabalhos de alunos dos cursos de Biblioteconomia e Administração Pública, nos quais foram aplicadas técnicas de análise espacial e análise multivariada.

Os alunos consideraram que a nova metodologia aplicada também se mostrou muito mais eficiente do ponto de vista da aprendizagem e aplicação, como pode ser percebido pelos depoimentos transcritos abaixo:

Aluna de Ciências Ambientais - $5^{\circ}$ período: “- Eu gostei muito da disciplina porque pude usar os conhecimentos que aprendi na Estatística em outra disciplina. Isso me ajudou muito."

Aluna Biomedicina - $3^{\circ}$ período: “- Agora a gente aprende de fato, porque são trabalhos práticos. Antes, a gente estudava só para tirar a nota, agora como a gente faz muito trabalho, a gente realmente aprende."

Aluna de Biologia - $6^{\circ}$ período: “- Agora que eu fiz pela segunda vez a disciplina, eu consigo relacionar o teste estatístico com a ecologia e genética." 


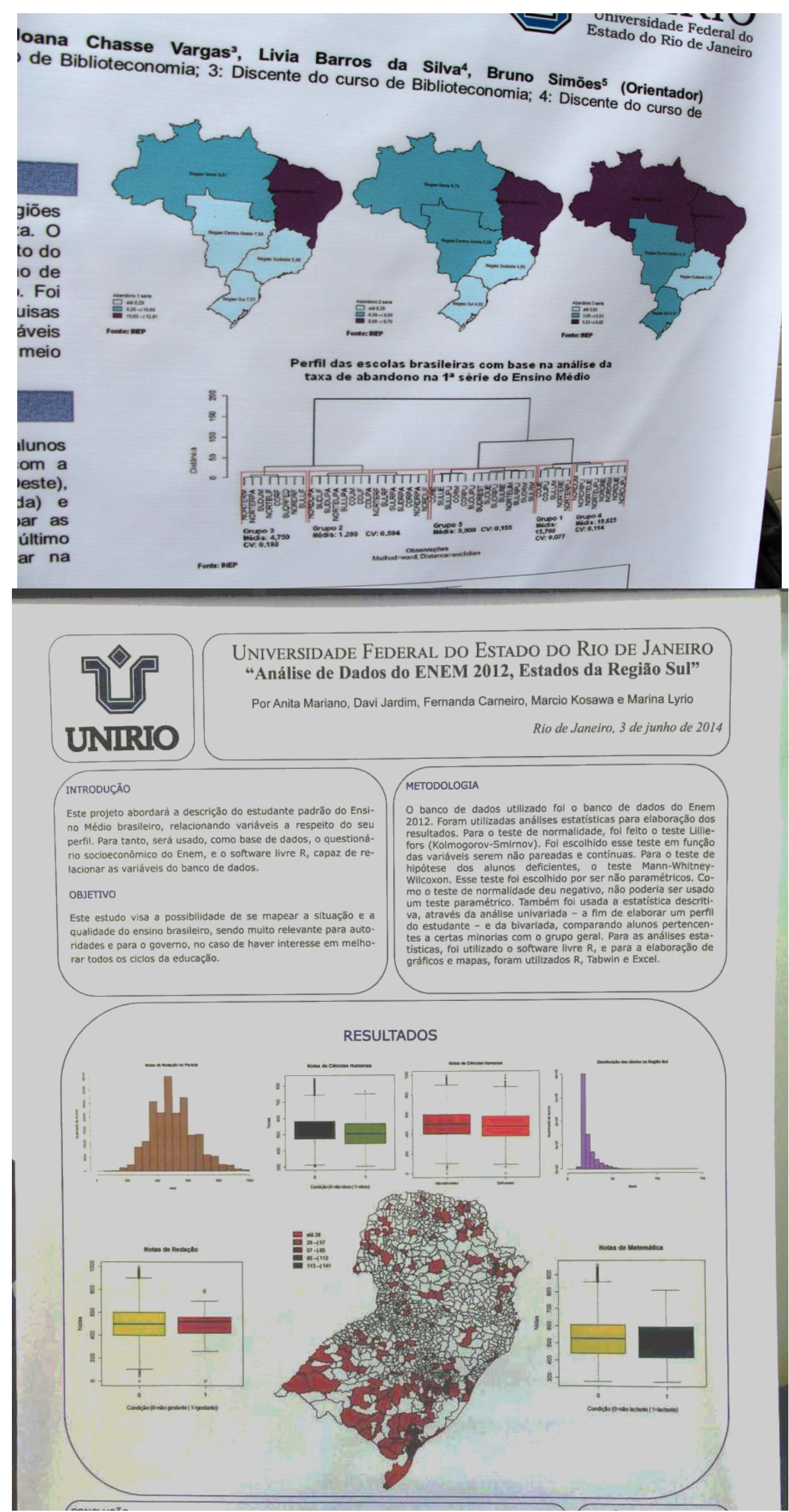

Imagem 3. Pôsteres apresentados pelos alunos da disciplina de Estatística, UNIRIO- 2014. 


\section{CONCLUSÃO}

O planejamento colaborativo permitiu a elaboração de uma nova metodologia de ensino da Estatística e nossa experiência, com essa nova metodologia possibilitou uma mudança positiva, tanto dos docentes, que antes atribuíam aos discentes todas as dificuldades enfrentadas, como dos discentes, que também não assumiam suas responsabilidades pelo ato de aprender. Neste processo, ao estarem muito mais envolvidos com a aprendizagem, motivação e a metodologia disponibilizadas, os docentes se transformaram em Educadores Estatísticos. A utilização prática da Estatística fez com que os alunos passassem a compreender, com muito maior clareza, a importância da disciplina em suas áreas específicas. Passaram a enxergar a Estatística não mais como uma matéria difícil e sem nenhuma relação com suas áreas de estudo, mas sim como uma ferramenta útil, que os permite entender melhor como aplicá-la em suas áreas de atuação.

\section{REFERÊNCIAS}

Bouhhuijs, P., Schmidt, H., \& Berkel, H. (1993). Problem-Based Learning as an Educational Strategy. Maastricht: Network Publications.

Donato, F. A. S., Rossi, M. A. M., \& Bezerra, E. P. G. (2007). Processo de palnejamento colaborativo sobre gestão dos riscos na cadeia de suprimentos, Encontro nacional de engenharia de produção, Foz do Iguaçu.

Julianelli, L. (2006). Desafios para Planejamento de Iniciativas de Colaboração no Processo de Planejamento da Demanda. Artigo Coppead/UFRJ.

Thomas, J. W. (2000). A review of research on project-based learning. disponível em http://www.newtechnetwork.org.590elmp01.blackmesh.com/sites/default/files/dr/pblresearch2 .pdf, acessado em 15/02/2012. 